\title{
Study on Chinese University Students' Privacy Protection from Intercultural Perspective
}

\author{
Huang Fang \\ College of Foreign Language \\ Qingdao Agricultural University \\ Qingdao China \\ huang311fang@163.com
}

\author{
Zhao Chen* \\ Science and Information College \\ Qingdao Agricultural University \\ Qingdao China \\ Zhao918chen@163.com
}

\begin{abstract}
Privacy protection arouses a prevailing concern among intercultural communication scholars and educators in the globalization age. Privacy protection is of great significance in keeping harmony between administrators and students in Chinese universities. Collectivism value orientation and the benevolence idea influence Chinese social behaviors which are characterized by the neglects of individual's privacy protections. Defects of Chinese legislation in privacy and lacks of legal consciousnesses for both administrators and students are major causes resulting in privacy invasions in Chinese universities. University administrators are supposed to insist the proper legal administrations and take students' privacy protections into considerations for the sake of scientific, humanized and institutionalized administration.
\end{abstract}

Keywords-privacy protection; collectivism; administrators; students

\section{INTRODUCTION}

Influenced by different value orientation, privacy protection awareness varies from nation to nation. During 1990, in response to ever-increasing awareness about the globalization of surveillance, more than a hundred privacy experts and human rights organizations from forty countries took steps to form an international organization for the protection of privacy (Bunnett, 1992) ${ }^{[1]}$. Since then, privacy protection issues have been paying prevailing concerns in the world. With the deep researches into privacy protection issues, educators, administrators and even law makers are trying to figure out appropriate and effective ways to handle privacy protection issues based on different value orientation, norms and social practices.

In China, with the opening-up policy and the speedy economic development, people's concerns about rights and awareness of intercultural communication have been aroused significantly. University students are placing increasing emphases on privacy protection issues in school education, and showing greater lengths to have their privacy respected and protected. Higher Education faces significant privacy and security challenges in the world ${ }^{[2]}$. Chinese educators have been concerning about students' privacy protection to a higher degree in Chinese Universities. Administrators and educators have been making great efforts to figure out appropriate ways to handle privacy issues effectively.

\section{PRIVACY PROTECTION}

\section{A. Definition of PrivacyProtection}

Privacy is defined as the ability of an individual or group to seclude them or information about themselves and thereby reveal them selectively. The boundaries and content of what is considered private differ among cultures and individuals, but share basic common themes.

Privacy protect is a hot topic discussed by scholars in different fields. The Privacy Protection Act of 1980 is a legislation passed in the United States that protects journalists and newsrooms from search by government officials ${ }^{[3]}$. The 1980 act protects "work products" and "documentary materials." A subpoena must be ordered by the court to gain access to the information. Warren and Brandeisy (1890) firstly put forward "The Right to Privacy" on the Harvard University's magazine named "Law Review"; it opened a door for people to discuss privacy protection ${ }^{[4]}$.

\section{B. Students' Privacy Protection}

Students are important components of any society, and they are entitled with the rights in privacy protections. Students' privacy protections indicate the prohibition of interference with their personal information, personal spaces, and personal businesses or activities that are unrelated to the public and group interests. The features of students' privacy protections are as follows: (1) Students are masters of privacy protections. (2) Objects of students' privacy protections include personal information, personal spaces, and personal businesses or activities. Students' names, genders, grades, health statuses, parental careers, family incomes, and family sizes are all included in the personal information. Personal spaces mainly contain personal fields, including bags, lockers, cases and the public spaces that individuals use appropriately. Personal businesses or activities mean individual things or activities that are unrelated to the public or group benefits. (3) Students' privacy protections embody their rights to hide, maintain and control. (4) Students' privacy has a feature of alienability and is confined by the right to be informed. Normally students' privacies are protected by law, and thus they are not allowed to be violated and invaded by anyone in any form. 


\section{CurRent Situation of Students’ Privacy PROTECTION}

\section{A. Students' Privacy protections in America}

American people have typical individualism value orientations and they believe individual interests are highly respected and are supposed to prevail over collective interests. Individualism value orientation indicates everyone has a right to privacy, laws and rights are supposed to be the same for all (Hofstede, 2008) ${ }^{[5]}$. People in America believe that their personal information and spaces are supposed to be respected and protected.

In 1974, the American congress passed the Family Educational Rights and Privacy Act (FERPA) to protect the confidentiality of students' records by preventing disclosure of personally identifiable information to third parties without prior parental consent. In addition, the act gives parents the right to inspect and review the educational records of their children (Taylor, 1996) ${ }^{[6]}$. FERPA gave students access to their education records, an opportunity to seek to have the records amended, and some control over the disclosure of information from the records. School employees are not allowed to divulge information to anyone other than the student about the student's grades or behavior, and schoolwork posted on a bulletin board with a grade is prohibited. Generally, schools must have written permission from the parent or eligible student in order to release any information from a student's education record.

\section{B. Students' Privacy Protections in China}

In China, Higher education law of the People's Republic of China was announced in 1998, more than 20 years later than American FERPA. The law also endowed universities the right to implement educational management. Chinese universities have autonomies in students' recruitments, students' status managements, degree awards, rewards and punishments, according to Xu Hongmei (2012) ${ }^{[7]}$. Generally speaking, Chinese universities form their unique internal administrative patterns, the relationship between university students and universities is usually considered as an internal one, therefore, there exist a great deal of conflicts between students' rights of privacy and university' administrators' rights to be informed.

Illegal opening and release of university students' personal information, particularly their heights, weights, contact information, medical histories, family financial statuses, grades, etc. are quite common in Chinese universities. Students, lacking of social experiences and consciousnesses of privacy protection, have been suffering from administrators' privacy invasions.

To further investigate students' privacy issues, a survey had been conducted among 100 randomly selected university students in Qingdao, China. All the participants are adults with the age varying from 19 to 22 . The questionnaire covered three main domains about privacy, namely, personal information, personal space, and personal activity or business. Participants were required to answer questions in the survey with their integrities and honesties.
According to the results, in terms of personal information, $70 \%$ of all the participants worried about their personal information might be released to the third party without being informed beforehand; over $50 \%$ of them admit they have received advertising texts from strangers; 35\% of them proved their exam grades had been released without their own permissions. One female student said, "My parents received my school report before I told them myself, and I have no idea why a university teacher still performed the same way as high school teachers did.” As for this problem, the administrator in chief did give a response, "The only reason we did so is to show our responsibilities for both parents and students. If the grades are not good to parents, students may be criticized by parents and feel really regretted, which may inspire them to study harder in the next term. This can also be an effective way to make students full of study motivation.” Another interviewed administrator said, "Of course we do not usually post school reports to parents in every term, we just post at the first year for the fresh students, because they are usually really lack of self-control at university when they firstly left their parents' supervisions. This practice proved to benefit students for their later study at university.” As far as family financial status is concerned, 50 of all the participants were voted as poor students to different degree, and $50 \%$ of them, that is $25 \%$ of all the participants hold strongly negative attitudes to the publicity of the name list for poor students.

TABLE I. PRIVACy SURVEY IN PERSONAL INFORMATION

\begin{tabular}{|c|c|l|l|}
\hline \multicolumn{4}{|c|}{ PRIVACY SURVEY IN PERSONAL INFORMATION } \\
\hline $\begin{array}{l}\text { Worry about } \\
\text { Information } \\
\text { release }\end{array}$ & $\begin{array}{l}\text { Texts from } \\
\text { strangers }\end{array}$ & $\begin{array}{l}\text { Grade } \\
\text { release }\end{array}$ & $\begin{array}{l}\text { Dispproval of } \\
\text { financial status's } \\
\text { publicity }\end{array}$ \\
\hline \multicolumn{1}{|c|}{$70 \%$} & $50 \%$ & $35 \%$ & $25 \%$ \\
\hline
\end{tabular}

University students' personal spaces are also proved to be invaded significantly in China according to the survey results. University administrators seek for possible excuses and pretexts to interfere with students' personal spaces, for instance, ensuring teaching quality, avoiding potential safety hazard, and reinforcement of dormitory administration are the excuses for administrators to be usually used. The survey results also indicate that some universities administrators even install monitoring devices in classrooms and dormitory floors. According to the survey, $80 \%$ of the participants felt uncomfortable about the monitoring devices. As for the living condition, Chinese students usually are not allowed to live outside of the campus, thus they live in a common dormitory which contains 6 or 8 students. Although the personal spaces are small, they do value them. Their personal spaces include personal chairs, desks, lockers, beds, etc. Because of Chinese university's sanitary examination regulation, some examiners and administrators let themselves in even when students were not in the dormitory. About this phenomenon, 68\% of participants proved they suffered from such kind of personal space invasion. What is worse, $23 \%$ of them proved their lockers had been examined 
secretly which made them angry about it, but unfortunately, they had nothing to do to protect their personal space.

TABLE II. PRIVACy SURVEY In PERSONAL SPACE

\begin{tabular}{|c|c|c|}
\hline \multicolumn{3}{|c|}{ PRIVACY SURVEY IN PERSONAL SPACE } \\
\hline $\begin{array}{l}\text { Disapproval of } \\
\text { monitoring devices }\end{array}$ & Dormitory invasion & $\begin{array}{l}\text { Lockers } \\
\text { secretly }\end{array}$ \\
\hline $80 \%$ & $68 \%$ & \multicolumn{2}{|c|}{$23 \%$} \\
\hline
\end{tabular}

As for personal activities or businesses, students over 18 years old are empowered rights to dominate. It is in accordance with law in China. However, the survey did not imply the equal results. The administrators insist students report the reasons for stepping out of the campus at weekends, which usually aroused students' complaints. A male student replied that, "University administrators always required us to describe specific reasons when asking for leaves at weekends, and they said it was for the sake of students' safeties. But we are already adults now and we can take responsibilities for ourselves. What is more, going out at weekend was not violating any regulations in our university. We have our rights to do what we plan to do, and it is not fair to report personal activities in crystal detail.” About privacy in personal activities in their free time, $85 \%$ of all the participants admitted they had experienced it, and $70 \%$ of them were bored with such universities’ inquiries.

TABLE III. Privacy SurVey IN PERSONAl Activities

\begin{tabular}{|c|c|}
\hline \multicolumn{2}{|c|}{ PrIVACY SURVEY IN PERSONAL ACTIVITIES } \\
\hline $\begin{array}{l}\text { Experience of inquiries into } \\
\text { personal activities }\end{array}$ & Disproval of inquiries \\
\hline $85 \%$ & $70 \%$ \\
\hline
\end{tabular}

Based on the survey, it is beyond any doubt that Chinese university students are discontent with their privacy protection to a very large extent. University's administrations and regulations are in conflict with students' rights of privacy.

\section{REASONS FOR STUDENTS’ PRIVACY INVASION}

The reasons for the serious problem in university students' privacy issues are analyzed as follows:

\section{A. Collectivism value orientation in China}

Compared with most western people who believe in individualism, Chinese people highly value collectivism, influenced by Confucian ideas. According to Gudykunst (2007), collectivists often perceive individualists to be too intimate, whereas individualists frequently feel that collectivists behave too distantly ${ }^{[8]}$. Besides, benevolence is the core idea in Confucianism, which indicates people in the group try their best to keep harmony and avoid hurting each other's face. Therefore, students are educated from the early age to pay more attention to the interests of the whole group, even sacrifice their individual interests if necessary.
Improving students' learning outcomes and getting along well with other people in the group are significant purposes in school education.

Privacy issues seem to be less important or minor things for Chinese students and educators. Large power distance between administrators and students are also featured by collectivism. Chinese students highly emphasize hierarchy and authority, which explains students' choices of keeping silence and compromise when they have strong complaints about administrators' privacy invasions.

\section{B. Defects of Legislation in Privacy Protection}

Influenced by collectivism value orientation, there is not a systematic legal document in terms of university students' privacy protection in China. It is comparatively ambiguous in defining of the right of privacy in China and cases about privacy infringement were usually determined as reputation infringement. Universities have duties to establish appropriate rules and regulations based on the law for the purpose of performing educational function. University students' privacy rights have not been properly protected as their independent personal rights in China and their privacy protection have been facing a lawless circumstance.

\section{Weak Legal Consciousness of University Administrators}

Professional backgrounds of the administrators in Chinese universities vary to a large extent. Most of them are graduates from educational and psychological majors. Universities in China usually do not have special posts for law school graduates, so few of administrators have knowledge about the proper and legal administrative methods. In addition, universities seldom carry out the professional legal trainings for both administrators and students. Therefore, administrators just follow the old stereotypes when handling issues and making some rules. Weak legal consciousness has been a significant problem causing students' privacy invasion.

The rights to be informed are considered as the bases for university administration. Students are required to fill in necessary personal information in detail at the enrollment. This personal information inevitably involves privacy issues. In the daily administration, teachers and administrators may use this personal information. Take tuitions for instance, fresh students' tuitions are usually required to be deposited in a given bank account. In fact, when their bank accounts are transacted, parts of students' personal information have already been delivered to the banks. Traditional university administrations are very rigid and stereotyped, and they seldom take students' privacy issues into considerations, thus, complains, even antipathies can be aroused if administrators and students are not efficiently communicated.

\section{University Students's Legal Consciousness Lag}

Chinese educational system has been questioned due to its deficiency of training students' comprehensive qualities. Parents, school administrators and even students themselves have been putting great emphases on academic learning 
outcomes, and they all neglect the training of legal consciousness. The primary task for students is always grades. Parents and students compromise other benefits and even rights for the improvement of students' learning. This social practices form stereotypes as time goes on, and even when they grow into university students, they are still unaware of the proper rights they hold. Students take it for granted on administrators' invasion in their privacy, as long as their behaviors are in accordance with university's rules.

\section{Strategies to StREngthen StUdents’ Privacy PROTECTION}

Legislative perfection in privacy protection is significantly indispensable in China since Chinese people are lack of privacy awareness. Chinese university administrators are supposed to stick to some principles: (1) Principle of legitimacy. Personal information of students should be acquired in the due process, and they are not publicized unless the permission of students. Administrators should also consider the ways of publication. (2) Principle of democracy. University administrators are supposed to coordinate and communicate with students effectively, and give priority to students' privacy issues. (3) Principle of protection. As for students' grades and family financial statuses, administrators should balance their rights to be informed and students' privacy rights. Give priority to students' privacy if possible. (4) Principle of keeping cautious. University administrators should make some emergency rules to handle problems of privacy protection invasion.

Both university students and administrators should improve their legal consciousnesses of privacy protections. Regular professional lectures about privacy issues are very helpful strategies to improve their legal consciousnesses. Brain gain of legal professionals and consultants are also necessary in most Chinese universities. On one hand, they help ensure administrators' legal administrations and considerations of students' privacy issues. On the other hand, students may learn to appeal in a proper way to protect their privacy issues.

University administrators should always holding on student-centered theory and put it into practices. Students' personal information, personal spaces and personal activities are supposed to be well respected and protected. Administrators should foster the service awareness and value students' democratic participations in their social and campus lives.

University students' privacy protections are worthy of public concern in China. Whether students' privacy issues are properly respected and protected affect harmony between administrators and students. Discussion of the current regulations and encouragement of students' involvement in the revise of university's regulations can promote harmonious campus atmosphere.

\section{ACKNOWLEDGMENT}

Sincere appreciation should be expressed to my family members for their permanent assistances and helps in the paper composition process. Besides, I will express my gratitude to all the research participants who are university students in Qingdao for their timely involvement and response. Without my family members' encouragement and students' help, the paper could not be accomplished in time and be sent to the 2013 International Conference on Education Technology and Management Science.

\section{REFERENCES}

[1] Colin J. Bennett. "Regulating privacy: data protection \& public policy in Europe and the United States”. Cornell University Press. pp. 248, 1992.

[2] Mary J. Culnan and Thomas J. Carlin, "Online privacy practices in higher education: making the grade?" in Communication of the ACMN, vol. 52, February 2009.

[3] "The Privacy Protection Act of 1980". Electronic Privacy Information Center. July 25, 2003. Retrieved 2010.

[4] http://zh.wikipedia.org/wiki/\%E9\%9A\%B1\%E7\%A7\%81\%E6\%AC \%8A_(\%E7\%BE\%8E\%E5\%9C\%8B)

[5] Geert Hofstede, Culture's Consequences: Comparing Values, Behaviors, Institutions and Organizations Across Nations, $2^{\text {nd }}$ ed., Shanghai Foreign Language Education Press, 2008, pp. 251.

[6] Taylor, B. B.. Education and the law: A dictionary. Santa Barbara: ABC-CLIO, 1996.

[7] Xu hongmei and Li siying, "Study on University students" privacy protection”, Journal of Yangtze University (Social Sience), vol. 11, 2012.

[8] William B. Gudykunst, Cross-Cultural and Intercultural Communication, $1^{\text {st }}$ ed., Shanghai Foreign Language Education Press, 2007, pp.113. 